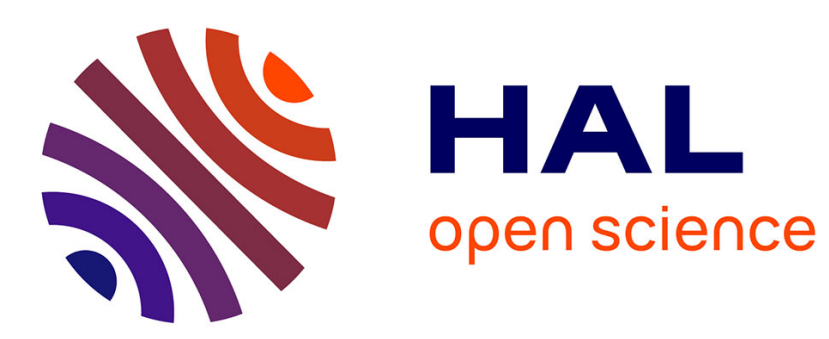

\title{
Modélisation en Electromagnétisme
}

F. Rioux-Damidau

\section{- To cite this version:}

F. Rioux-Damidau. Modélisation en Electromagnétisme. Revue de Physique Appliquée, 1990, 25 (7), pp.564-564. 10.1051/rphysap:01990002507056400 . jpa-00246220

\section{HAL Id: jpa-00246220 https://hal.science/jpa-00246220}

Submitted on 1 Jan 1990

HAL is a multi-disciplinary open access archive for the deposit and dissemination of scientific research documents, whether they are published or not. The documents may come from teaching and research institutions in France or abroad, or from public or private research centers.
L'archive ouverte pluridisciplinaire HAL, est destinée au dépôt et à la diffusion de documents scientifiques de niveau recherche, publiés ou non, émanant des établissements d'enseignement et de recherche français ou étrangers, des laboratoires publics ou privés. 


\section{REVUE DE PHYSIQUE APPLIQUÉE}

\section{Modélisation en Electromagnétisme}

La modélisation est devenue essentielle pour les études et conceptions en électromagnétisme comme dans bien d'autres domaines. Elle permet en général de remplacer une expérimentation sur maquette réelle, forcément soumise à de nombreuses contraintes, par des calculs où les paramètres peuvent être modifiés à volonté. Si dans quelques cas assez exceptionnels, elle peut se faire analytiquement, elle nécessite la plupart du temps l'emploi de techniques numeriques. Dans les années 70, celles-ci étaient limitees aux systèmes bidimensionnels ; elles se sont étendues, dans les années 80 , aux systèmes tridimensionnels devenus accessibles grâce à l'évolution des ordinateurs. Ce numéro spécial de la Revue de Physique Appliquée regroupe un certain nombre d'articles consacrés à divers aspects de la modélisation. Ils concernent des perfectionnements en 3D (génération de maillages, étude de différentes formulations pour les courants de Foucault et pour la magnétostatique) des modélisations de couplages entre phénomènes électromagnétiques et mécaniques ou entre équations électriques et magnétiques, des applications de la modélisation numérique ou analytique à l'étude de turbogénérateurs, de machines à rotor massif, de machines à aimant ou de capteurs inductifs et enfin, la présentation de techniques et codes adaptés aux guides d'onde (multipôles).

Sans prétendre à l'exhaustivité, ces contributions complètent les nombreux articles déjà publiés par la Revue de Physique Appliquée dans le domaine de la modélisation en électromagnétisme.

F. Rioux-Damidau 